\title{
Comparative study of resistance to antibiotics of strains of Klebsiella isolated in urinary and respiratory infections
}

\author{
Dan Dumitru Hurezeanu ${ }^{1 *}$, Livia Dragonu' ${ }^{1}$ Carmen Canciovici², Daniela Ristea ${ }^{3}$, Doina Ene ${ }^{2}$, Mioara Cotulbea², \\ Magdalena Peter ${ }^{2}$, Felicia Dumitraşcu², Maria Bălan² \\ From The 9th Edition of the Scientific Days of the National Institute for Infectious Diseases Prof Dr Matei Bals \\ Bucharest, Romania. 23-25 October 2013
}

\section{Background}

A study of the dynamics of antibiotic resistance of Klebsiella pneumoniae is necessary in order to adapt therapeutic recommendations.

The objectives of this paper pursue the comparative analysis of resistance to antibiotics of strains of Klebsiella pneumoniae isolated in urinary and respiratory tract infections.

\section{Methods}

Retrospective study conducted between 01 January 2013 - 31 August 2013 on the resistance of Klebsiella pneumoniae isolated from sputum (96 strains) and urine culture (163 strains) from patients hospitalized in the "Victor Babeș" Clinical Hospital of Infectious Diseases and Pneumology, Craiova. The antibiogram was performed by classical diffusimetric method.

\section{Results}

The resistance to antibiotics was higher in Klebsiella pneumoniae strains isolated from urine culture compared to those isolated in respiratory infections in case of: a) beta-lactams (ceftriaxone $45.2 \%$ versus $69.5 \%$, cefaclor $36.7 \%$ versus $52.9 \%$, cefuroxime $49.3 \%$ versus $61.9 \%$, cefoperazone-sulbactam $70.6 \%$ versus $85.7 \%$, piperacillintazobactam $58.1 \%$ versus $75.5 \%$, aztreonam $45.8 \%$ versus $66.6 \%$, ampicillin-sulbactam $46.4 \%$ versus $69.1 \%$, amoxicillin-clavulanic acid $26.8 \%$ versus $40.5 \%$ ), b) quinolones (ciprofloxacin $61.8 \%$ versus $83.4 \%$ ), c) co-trimoxazole ( $45.4 \%$ versus $82.8 \%)$. The sensitivity profile showed no major differences for: colistin (82.7\% versus $81.6 \%)$,

* Correspondence: dan_hurezeanu@yahoo.com

'University of Medicine and Pharmacy Craiova, Romania

Full list of author information is available at the end of the article carbapenems (95.2\% versus $97.8 \%$ ) and aminoglycosides (72.3\% versus $75.8 \%)$.

\section{Conclusion}

The sensitivity of Klebsiella pneumoniae to carbapenems remained high, recommending the use of these antibiotics for infections with resistant germs. The empirical use of antibiotics for urinary tract infections and invasive urological maneuvers may explain the increased resistance profile of germs isolated from urine culture.

\section{Authors' details}

"University of Medicine and Pharmacy Craiova, Romania. "Victor Babeş" Clinical Hospital of Infectious Diseases and Pneumology, Craiova, Romania. ${ }^{3}$ Emergency Clinical Hospital, Craiova, Romania.

Published: 16 December 2013

\section{doi:10.1186/1471-2334-13-S1-P39}

Cite this article as: Hurezeanu et al:: Comparative study of resistance to antibiotics of strains of Klebsiella isolated in urinary and respiratory infections. BMC Infectious Diseases 2013 13(Suppl 1):P39.

Submit your next manuscript to BioMed Central and take full advantage of:

- Convenient online submission

- Thorough peer review

- No space constraints or color figure charges

- Immediate publication on acceptance

- Inclusion in PubMed, CAS, Scopus and Google Scholar

- Research which is freely available for redistribution

\section{Ciomed Central}

